\title{
Lean Implementation Barriers and the duality of lean in an Organizations
}

\author{
Williams Austin ${ }^{1, *, \dagger}$ and Faith C. Adebayo ${ }^{2, \dagger}$ \\ ${ }^{1}$ Middlesex University, London and ${ }^{2}$ Kemmy Business School, University of Limerick, Ireland \\ *corresponding author: williams.austin@gmail.com \\ ${ }^{\dagger}$ Auhtors Contributed equally.
}

\begin{abstract}
Lean strategy is all about elimination of waste and redundant processes; competitive benchmarking, introducing continuous improvement programs, preventive maintenance optimization, cycle time reduction, just-in-time (JIT), new process improvement, quality management programs, value engineering, self-directed work team, total quality management. Background: The study investigates how people and duality of lean impact lean implementation in organizations, looking at the case of the food processing manufacturing firms in Ireland. Method: To achieve the objective, the study employed Structural Equation Modelling (PLS-SEM) using data collected from 340 questionnaires collected from food processing firms in Ireland. Results: It was discovered from the study that factors hindering the implementation of lean could be in the form of poor communication strategy within organization, organizational culture, organizational knowledge, management support, policies on human development. The paper concludes that lean implementation does not have a stand-alone methodology, but the existence or lack of the identified factors may make or hinder the successful implementation of lean especially in the food processing manufacturing companies in Ireland.
\end{abstract}

Key words: Lean implementation; Duality of Lean; Human aspect of lean; barrier to lean implementation; Partial Least Squares Structural Equation Modeling (PLS-SEM); Ireland.

\section{Introduction}

This study aims to determine the barriers to lean implementation in the organization and the extent duality of lean is manifested in lean implementation. The twenty-first-century business environment requires that an organization must adopt lean approach to its business process; cutting down redundant processes, regulation, cost, customer dissatisfaction, while providing competitive services and products to all customers. Confronted with this complex business environment, organizations are fiercely competing for market share. Customers are becoming more loyal to organizations that deliver more value with less price (Mrugalska and Wyrwicka; 2017).

Learn which originates from Toyota is all about giving more value with fewer resources; an ideology built on the grounds of eradicating all known waste in the production process (Bhamu and Sangwan; 2014; Andersen and Rovik; 2015). Filho et al. (2016) view lean as an organizational culture built around continuous learning and improvement in the flow of work processes. Elimination of any process that does not add value (called waste or Muda) in the process of production of goods or services. Such wastes include defects that require an overhaul, overloaded movement of materials, excess waiting time, accumulated or overproduction leading to increased inventory (Mrugalska and Wyrwicka; 2017). Lean is therefore value addition to all stakeholders while reducing cost (Bhamu and Sangwan; 2014). Andersen and Rovik (2015) stated that lean management is associated with effort such as bottleneck removal, competitive benchmarking, continuous improvement programs, preventive maintenance optimization, cycle time reduction, just-in-time (JIT), new process improvement, quality management programs, value engineering, self-directed work team, total quality management. 
The dynamics and fluctuating nature of twenty-first business environment put enormous pressure on businesses in Ireland to become much more agile to be equipped to conquer this threat. The value of harmonizing output to the requirements of the customers as well as being able to successfully deliver better quality services and at lesser time appears to be growing (Warcup; 2015). The obvious strategy to attain this target is the proper implementation of lean production, a methodology and culture that allows businesses to focus on minimizing waste within their production processes while simultaneously maximizing productivity (Andersen and Rovik; 2015). However, lack of lean implementation in most organization within the manufacturing sector has increased production, service, and distribution waste, lead times, higher operating cost, low quality products, and inefficient utilization of resources. Waste entails any processes and resources that don't add value (Mrugalska and Wyrwicka; 2017). According to Filho et al. (2016), lack of implementation of lean can be manifested in the form of poor substandard goods, growing inventories, huge cost of transportation, and an over-processing, which often result in customer displeasure, downturn in the share of the market and reduced profitability.

Despite the beauty of lean implementation and adoption in organization, large number of organizations has not embraced lean within their production process largely attributed to numerous challenges with lean implementation. These barriers to lean implementation has been largely debated in literature. Bhamu and Sangwan (2014) identified definitional issues, poor understanding of lean, poor communication strategy, and management style as leading causes of lean implementation failure. To Alkhoraif and McLaughlin (2018), the leading barrier to lean implementation is poor harmonization of the duality of lean - the people side and the technical side. Pakdil and Leonard (2015) noted that organizational culture like leadership impacts the success of lean implementation. Such culture and leadership factors include employee involvement in lean implementation, process decentralization, control, and standardization process, efficiency, continuous improvement policy, problem solving and analysis culture, monitoring, and control policy.

Our findings reveal that poor communication strategy within organization, organizational culture, knowledge transfer, and management, management support for lean implementation, policies on human development are among the leading barrier to lean implementation if they are not effectively managed. The study also found that lean is not a methodology as popularly referred in literature but a culture that could be integrated within the organization since lean emphasizes continuous leaning and innovation. The rest of the paper is therefore organised into; literature review - developing lean implementation framework and empirical findings on challenges to lean implementation. The methodology section will discuss the data collection and analysis strategy, the analysis and discussion section present and discuss the result, and the conclusion section provides summary conclusion based on the research result.

\section{Literature Review}

\section{1: Lean Concept}

Lean has it origin from Toyota manufacturing company who believes there is always room for further improvement in the manufacturing process whether the flow or the people aspect (Bhamu and Sangwan; 2014; Andersen and Rovik; 2015). Alkho- raif and McLaughlin (2018) noted that lean management can be traced back to 1800 with the work of Sakichi Toyoda who was dissatisfied with the output and process of his small weaving firm and designed a weaving machine that improves productivity as at that point in time. This was followed by his son designs which have capacity to stop the machine when the thread broke thereby reducing the number of poor cloth design production (Alkhoraif and McLaughlin; 2018). This was the same foundation at which Toyota was built upon. With the belief that a process can be improved to achieve further efficiency and effectiveness.

The lean concept is often associated or interchanged with lean thinking, lean production, lean process and lean management. Amade et al (2019) noted that several lean concepts are often used interchangeably although they have different meaning and contexts which further deepen the reasons while most lean implementation fails as the lean implementer lack sound knowledge of the concept. Lean entails waste elimination, a process of reducing the cost of any activity without reducing the value of the activity (Pakdil and Leonard; 2015).

Lean can be viewed also from manufacturing perspective. For instance, (Asna et al.; 2015) noted that "lean" is an approach that employs fewer resources to generate the same level of outputs as those set up by a conventional large-scale production structure, thus expanding the gamut of similar manufactured goods for the end-user. Lean manufacturing is also viewed as the process of reducing the idle time, waste, and time in the production of goods. It is often interchanged with lean production which is an idea built around removing every known waste in the production process or a principle in which all manufacturing staff works with one another to reduce waste (Pakdil and Leonard; 2015). The word lean production is developed to reflect minimal human effort in the company, less storage capacity, less expenditure on equipment, less progressive inventory, and less development hours to design a new commodity in less time.

Lean has also been called "lean management" which entails the removal of every known waste, inefficiencies, improves the system and simultaneously improve the organization output without necessarily increasing the input (human and physical capital) (Chanegrih and Creusier; 2016). Thus, Lean can be viewed as a theory, a methodology, a solution to better processes, a procedure, as well as a corporate strategy. Lean process entails imbibing the culture of lean into organization learning and culture. Lean deals with organizational culture built around continuous learning and improvement in the flow or work process. In order words elimination of any process that does not add any value (called waste) in the product or service. A lean organization is organization that think about elimination of every possible waste, how to improve the process and provide all necessary tools and support to eliminate any idle process. In summary, lean whether lean production, manufacturing, process, and management is concerned with waste reduction in the production process where every organization resource is optimally utilized to its full potential through an innovative approach of managing the resources. Lean cannot be successfully implemented without adequate respect for the human factor - the human resources will be properly motivated to deploy their full potential.

\subsection{Lean Implementation Barriers}

Several literature have debated the barrier to lean implementation regardless of organization size, region, While Lean has shown great success in production, deployment comes with plenty of challenges. There are common specific factors identified as the leading hindrance to lean implementation includ- 
ing but not limited to perception of lean, poor selection of improvement team members, poor understanding, lack of personal and professional skills, Hierarchy and management roles, Compartmentalization, or culture, poor communication, inadequate resources, lack of ownership, performance measurement and data collection, among others (Mrugalska and Wyrwicka; 2016; Jasti and Kodali; 2015; Stone; 2016).

For instance, (Jasti and Kodali; 2015) noted that organizational culture like leadership impacts the success of lean implementation. Such culture and leadership factors include; employee involvement in lean implementation, process decentralization, control and standardization process, efficiency, continuous improvement policy, problem-solving and analysis culture, monitoring and control policy (Shepherd; 2016; Pakdil and Leonard; 2015). A similar stance was earlier shared by Noori (2015) who insisted that lean implementation culture is the one who leverages on human resources of the organization in developing requisite skills and knowledge that gives the organization opportunity to compete through innovation and creativity in the marketplace. Shepherd (2016) noted that in building an effective lean culture, effective leadership behaviour and style combine with lean toolbox is required to achieve success the absence will lead to failure of the project.

On an individual level, one of the most common reasons predicted to cause the failure of lean implementation is the individual/ employee hard attitude towards change within the organization. Peabody (2019) noted that employee often resists change because of the thought that they will lose something of great value because of the change, poor understanding if the change and its process, believe that the change does not worth it and will not have any positive impact, and individual general averse to change. The idea is that convincing internal customer (employees) to welcome change and focus on discovering waste within the production process in meeting customer needs is often hard to achieve. When employee do not buy the change, they will not give the customers the required services they desire over time.

Another common challenge encountered in the service industry is the paucity of standardized procedures. It is also challenging for companies to work with systems and reduce the cost due to the size and sophistication(Amade et al.; 2019). There is need for organization to develop an improved method of tracking the service phases/point, this will facilitate the understanding of the ability of each of the employees and as such providing an avenue with which the best are engaged at each stage of the process. Although, there are other issues identified within the system that contribute to the complication of the lean system.

As noted earlier, employee and individual resistance to change greatly impact the lean process. Grove et al. (2015) noted that employees often see changes as disrupter of flow within the organization and because of the low appetite in most human to learn new things they often challenge lean process within the organization making most effort to implement lean to fail. Marodin and Saurin (2013) noted for success in lean implementation, the management needs to orient the employees on the needs for structural changes within the system that deliver more value and benefits to the organization customers (external and internal customers). Peabody (2019) argued that when employee understand that structural changes (lean) will improves their wellbeing and get them more result they will embrace it faster.

Another challenge to lean implementation as identified in literature is poor or ineffective communication within the different cadre of management within the system. For instance, Allu (2018) noted that most organization where lean implementation failed there is evidence of no effective coordination among senior managers/management and the operational/employees (Grove et al.; 2015). This reaffirm the assertion of Amade et al. (2019) that organization with standardized procedure of flow and procedure of introducing change tends to enjoy more success rate in the implementation of lean strategies compared to others.

The issues of ineffective communication as a hindrance to lean implementation can further be discussed as leadership/management issue. Stone 2012 noted that leadership style adopted within the organization further facilitates the adoption of lean within the organization. Poor management approach to lean commitment and transition greatly hampers lean adoption within the organization. Two biggest issues identified with management approach to lean is management poor knowledge of the changes lean strategies will mean to the organization productivity and whether the lean is compatible with the organization short term goals and market strategies. An understanding of the lean contribution to the organization overall health and not as a disrupter will determine the extent the management will push for the introduction of lean within the organization.

Organizational culture is another key factor inhibiting lean implementation in most developing countries organization. Bhasin (2012) and Stone (2016) argued that most organization understanding of the Toyota way is far below the philosophical perspective and institutional phenomenon compared to what most companies have expected, and that most struggling or short-lived strategies can be traced to culture. This can be linked back to the issues of definition and understanding of the concept itself. As defined by Marodin and Saurin (2013), the lean definition may require substantial translation efforts before adoption due to its poor inscriptions. To establish a consistent corporate direction and strategic methodology, top management participation in this initial transition process is essential if lean is to be related to policy. The disparity between viewpoints and probably the failure to exchange opinions makes it even more impossible for an entity to be guided in one direction, and to adequately develop a culture that recognises the individual differences. Ramadas and Satish (2015) identified role alignment as other challenges often faced in the introduction and implementation of lean within the organization. The author argued that while management often introduces lean, it is the middle and line manager that often facilitates the implementation of lean, though, not independent but in collaboration with the top management. The argument is that line and middle managers should focus their own decisions on the acts and not on senior management's statements, as it is their behaviour that will give direction on the real priorities and what will happen.

Another major challenge to lean implementation is the sidelining of the human side in favour of the toolbox (continuous improvement). Here is what Coetzee et al. (2016) noted, the true value for "continuous improvement" lies in the ability of the management to create and build an environment where changes triumph and where individuals can easily learn without any form of hindrance. This kind of environment cannot be created where there is no respect for the "people" the human side of the "Toyota way".

Therefore, Lean understanding as a toolbox for eliminating redundancy and improve the quality of manufacturing and operations is constrained in that it does not follow a program strategy or tackle management as a means that ensure sustainability (Chanegrih and Creusier; 2016). It can be seen as important to change management in a Lean framework to support the development of individuals, processes and attitudes required for organizational learning. This reaffirm the word of Isao Kato a trainer at Toyota who noted that if organiza- 
tion must succeed with lean there is need to work in the development of the human side of the organization by creating an environment where learning thrives. The argument is that it is nearly impossible to achieve a successful development of production without the development of the people and once an organization misses this aspect the lean implementation will fail.

\subsection{Lean Implementation Success Factors}

Lean implementation seems to be an important concept in institutions since it requires vast awareness, strong engagement, and an in-depth examination of issues. Lean is being adopted by many more institutions in the long term to increase efficiency, to minimize costs, great customer service and reliable wait times. A dedicated management is needed to support the companies to succeed in adopting Lean. Therefore, external support may offer another channel of viewing things and pass expertise to institutions through their inputs on the best approach to implementing lean. External support may be beneficial to improve corporate awareness of Lean in the short term; nevertheless, institutions should never be reliant on them as it is a constant long-lasting improvement process (Coetzee et al.; 2016).

It is important for organization to know that it is rare to implement lean as a short-term project. Through looking at incentives and constraints, there is need to function actively to reduce waste and raise responsibilities. Toyota, for example, introduced the lean approach in the 1950s with the target of reducing every redundant activity in the system. Optimal lean implementation relies on the use of successful lean methods under structure restraints and strategic objectives. A decision-making structure that relies on bottom-up initiatives (transformational leadership style), good track of quality reports, ensure reliability of vendors, as well as adapted managed system that connects salary bonuses to quality output is required for effective lean application. In addition, it is crucial to develop extensive production strategies both in content and scope that facilitate change adoption and transformation (Kumar; 2014). Successful implementation of lean demands significant changes at all levels as well as departments, including administrative and even cultural work issues.

Chanegrih and Creusier (2016) identified five phases of lean implementation which includes stabilization, continuous flow, coordinated output, pull method, and levelled production. Management needs to understand that for effective implementation of the Toyota way, the Toyota product design framework needs to be redesigned to fit each organization's individuality and incorporated into the entire system, recognizing the value of better-employed methods and techniques (Chanegrih and Creusier; 2016). Garcia and Bonavia (2015) noted that proper training and orientation of workers is a bedrock of all efforts for reform and seems to be key to effective lean adoption. Certain effective drivers include management's dedication to progress and active involvement in programs for development and society promoting independent research, or, in other terms, lean leadership.

\section{Research Method}

\subsection{Data Collection}

The study employed a deductive approach built on existing theories and a descriptive survey method in the data collection and generation. A deductive and descriptive survey are the best fit when the researcher is concerned with generating numbers for testing an hypothesis (Ridwan and Joseph; 2021). The population of the study is made up of all the managers or owners of 340 SMEs in the food processing industry in Dublin, Ireland. The study relied on a questionnaire from existing peer-review literature in developing the scale of the questionnaire. Other items added were first subjected to a pilot study of 5 manufacturing firms different from the study sample. Based on the feedback from the pilot study, some questions were rephrased to improve their clarity.

\subsection{Data Analysis}

Structural Equation Modeling (SEM) was used in conducting the analysis. The study relied on the most well-used SEM model - the covariance-based methods (Becker et al.; 2012). Following the work of Becker et al. (2012) Partial Least Squares Structural Equation Modeling (PLS-SEM) approach was selected since PLS-SEM requires the computation of construct scores for each latent variable in the path model. This method is capable of handling non-normal data and is flexible enough to scrutinize small samples. Thus, this method was selected due to (a) the theoretical model is not well-formed; (b) there is an uneven number of indicators; (c) there are different modes of reflective and formative constructs; (d) the data distributions are not normal and not highly demanding concerning sample size, and (e) modeling is flexible beyond the firstgeneration techniques.

Accordingly, there are two approaches to reporting PLS-SEM. The first-tier is by reporting the appropriateness of the second-order construct in PLS-SEM. Preliminary considerations involve the use of repeated indicator approaches with Mode $B$ and the path weighting scheme which would ensure that no biased results will occur (Becker et al.; 2012). The second-tier entails reporting the considerations and rules of thumb in assessing the results of PLS-SEM.

At first, the focused on the second-order construct the formative relationship. The conceptual model has two second-order constructs. The first is the barrier with three first-order construct (communication, culture, and resources) and the second is the human factor (management and strategies/communication). The study also adopted the repeated indicator approach to estimate the construct scores of a second-order construct because the observed variables (or indicators) do not exist. Then, the mode of measurement for the second-order repeated indicators is Mode $\mathrm{B} /$ formative constructs. Next, path type was used as the inner weighting for the PLS-SEM algorithm. The repeated indicator approach using Mode B together with the path weighting scheme results in the most paramount parameter estimates for the root mean squared error (RMSE) and mean absolute relative bias (MARB) (Abu et al.; 2021). Following the work of Abu et al. (2021), since the second-order items were unequal in the two categories, the manifest variables were used twice: firstly, for the first-order latent variable ("primary" loadings) and secondly for the second-order latent variable ("secondary" weights). And the last step in this category is assessing the second order constructs using the manifest variables.

To evaluate the model, both the measurement and structural model were evaluated following previous literature (Becker et al.; 2012). At first, both convergent and discriminant validity were used to assess the measurement model (Duarte and Amaro; 2018). There are two model constructs for construct validity which are the first-order construct (reflective 


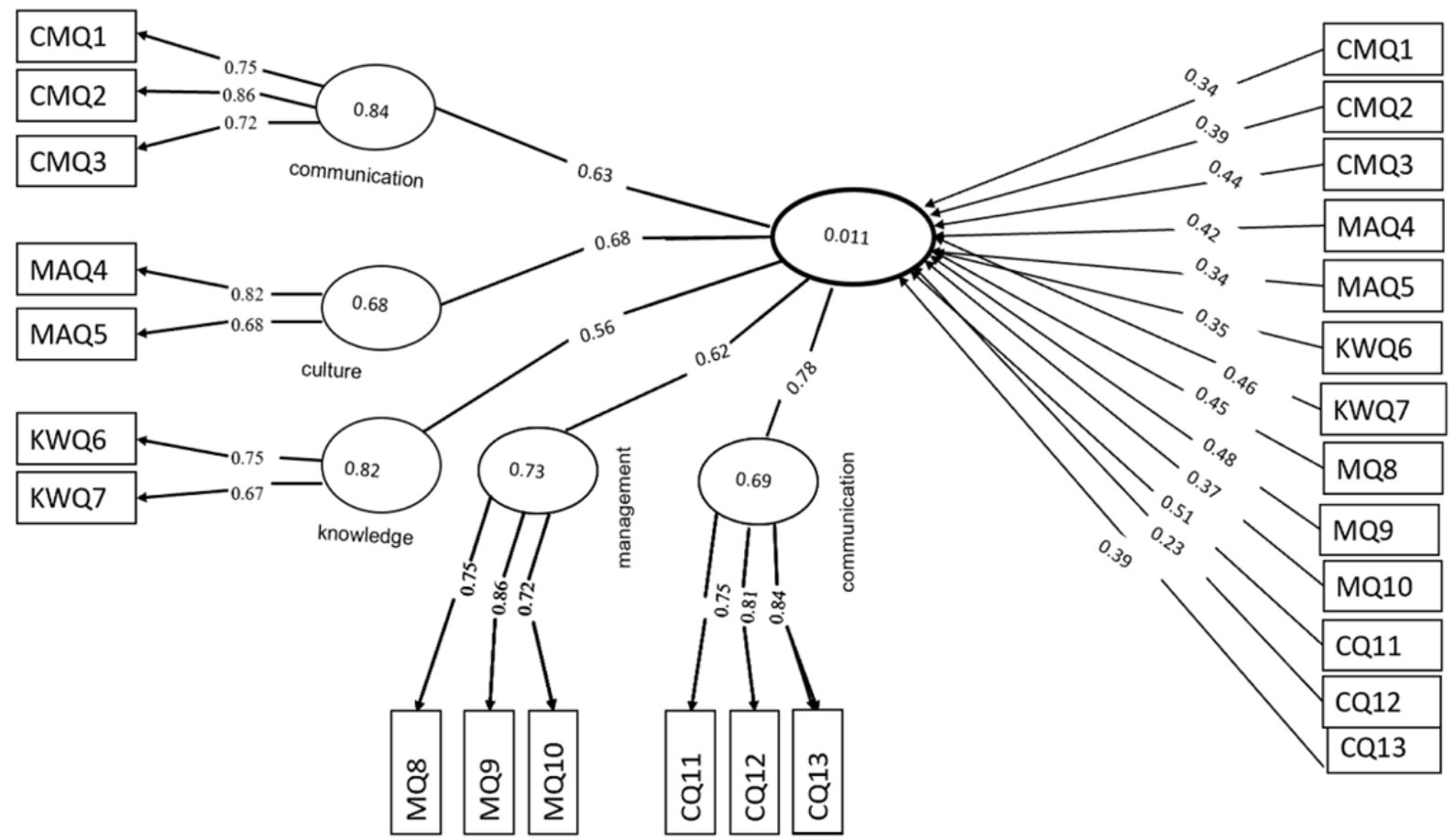

Figure 1. Structural Equation Model Path

measurement model) and the second-order construct (formative measurement model). The construct validity of the reflective measurements was confirmed by loadings, CR and AVE. For the reflective first-order construct, the measurement would be acceptable if the loadings of the indicators were above the threshold of 0.5 ((Abu et al.; 2021). Subsequently, the formative measurements were confirmed by VIF and path weight and the detail is presented in Table 1.

\section{Analysis and Discussion}

Given that the first order construct is uneven, the Mode B repeated indicator approach using path weighting scheme on the second-order constructs was used. The measurement model was first assessed following the suggestion of Jayasingam et al. (2018). The recommended factor loadings value was set at $(>0.5)$, the CR at $(>0.7)$, and the AVE at (>0.5). The result of confirmatory factor analysis, and the measurement properties of items and their internal consistency reliabilities are presented in both Figure 1 and Table 2. The result reveals that all the factor loading's were 0.6 or higher, which were above the threshold of 0.5 suggested by Jayasingam et al. (2018). Moreover, all the Convergent validity test values and discriminant value are all well above 0.7 the highest suggested value Abu et al. (2021).

The least recorded first order construct was 0.68 which is above the 0.6 threshold. Again, the CR varied between 0 and 1 . All the CRs had values above 0.7 (Scholtz et al.; 2016), and none of the CR values were above 0.9 which is an undesirable value. All the AVE assessed were higher than the critical value of 0.5 (Scholtz et al.; 2016). The implication is that the key constructs capture more construct-related variance than error variance.

The correlation among the first order construct were tested using the VIF and path weight (Table 3). Firstly, all the predictor constructs' VIF values were assessed to ensure that there is no collinearity issue between the constructs' formative indicators. As all the VIF values were below the more conserva- tive threshold of 3.3. As in Table 3, there indication of multicollinearity problems.

\subsection{Structural Equation Model}

The test of the structural model includes estimates of the path coefficients, an indication of the model predictive power and relationship between the dependent and independent variables, and the $R^{2}$ values, which represent the amount of variance explained by the independent variables (Scholtz et al.; 2016). Together, the $R^{2}$ and the path coefficients (loadings and significance) indicate how well the data support the hypothesized model. Figure 1 explains the results of the test of the hypothesized structural model. Table 4 represents the results of an assessment of structural path model. This table indicates that all the construct developed to assess the significance of the construct in determining the barrier to lean management are significant at $\mathrm{p}=0.05$. As expected, the majority of influencing factors have a significant positive effect on the lean implementation.

\section{Conclusion and Policy Implication}

SEM methodology was employed in analysing the challenges to lean implementation in food processing manufacturing firms in Ireland. The findings reveal among others that leans implementation in food processing firms in Ireland has been plagued by five different class of issue with different sub-components. It was revealed that communication strategy, organizational culture (like the ability to adapt to changes), knowledge sharing and competence within the employees and existence of team spirit, management support for lean implementation, and respect for human factor are key to successful implementation of lean in the industry.

In particular, like earlier researchers, it was found that lean tools such as JIT, SCM, TQM and TPM are found essential in the manufacturing industry, there are also factors that 
Table 1. Measurement and structural model cut-off values/recommended

\begin{tabular}{ll}
\hline Test type & Description \\
\hline & Convergent validity (CV) \\
Reflective indicator loading & Values for loadings are set at $>0.5$ \\
Composite Reliability (CR) & Recommended CR values within $0.70-0.90$ are satisfactory \\
Average Variance Extracted (AVE) & AVE for each construct should be $>0.5$ \\
& Discriminant validity (DV) \\
Heterotrait- monotrait ratio of correlations (HTMT) & For conceptually similar constructs: HTMT $<0.90$. \\
Variation inflation factor (VIF) & Probable (i.e., critical) collinearity issues when VIF $>5$ \\
significance of weights & p-value < o.05 or the 95 percent confidence interval. \\
& Structural Model \\
Coefficients of determination (R2) & $R^{2}$ result is equal to 1 for repeated indicator approach \\
$Q^{2}$ value & Blindfolding-based cross-validated redundancy measure $\left(Q^{2}\right)$ \\
& Values higher than zero denote meaningful \\
& Values larger than $0,0.25$ and o.50 indicate small, \\
& medium, and large predictive accuracy of the PLS path model. \\
& $Q^{2}$ predict values $>$ indicate that the model outperforms the benchmark \\
\hline
\end{tabular}

Source: Authors.

Table 2. The measurement model of first-order constructs

\begin{tabular}{|c|c|c|c|c|c|}
\hline Contruct & & Items & Loadings & $\mathrm{CR}$ & AVE \\
\hline \multirow[t]{3}{*}{ Effective communication } & Poor communication among the lean stakeholders. & CMQ1 & 0.75 & 0.835 & 0.562 \\
\hline & Poor infrastructural integration in communication. & CMQ2 & 0.86 & & \\
\hline & Process decentralization & CMQ3 & 0.72 & & \\
\hline \multirow[t]{2}{*}{ Organizational culture } & Weak link between lean and the organization's culture & MAQ4 & 0.82 & 0.810 & 0.524 \\
\hline & Problem solving and analysis culture & MAQ5 & 0.68 & & \\
\hline \multirow[t]{2}{*}{ Knowledge } & Employees' poor competence and knowledge of lean implementation & KWQ6 & 0.75 & 0.875 & 0.539 \\
\hline & Poor knowledge and selection team in lean & KWQ7 & 0.67 & & \\
\hline \multirow[t]{3}{*}{ Management } & Management and employee negative perception of lean & MQ8 & 0.75 & 0.852 & 0.523 \\
\hline & Poor management support for lean & MQ9 & 0.86 & & \\
\hline & Management failure to create safe environment & MQ10 & 0.72 & & \\
\hline \multirow[t]{3}{*}{ Human Factor } & Employees are trained on lean implementation & CQ11 & 0.75 & 0.832 & 0.541 \\
\hline & Existence of continuous learning and improvement environment & CQ12 & 0.81 & & \\
\hline & Feedback approach is employed & CQ13 & 0.84 & & \\
\hline
\end{tabular}

Source: Authors

Table 3. The measurement model of second-level constructs (formative).

\begin{tabular}{llllll}
\hline & Colliniarity (Iner VIF) & Statistical Sig. Weights & P-value & Conf. Level (5\%) & Conf. Level (95\%) \\
\hline Effective Communication & 1.141 & 0.63 & 0.001 & 0.426 & 0.425 \\
Organizational Culture & 1.120 & 0.68 & 0.001 & 0.510 & 0.611 \\
Knowledge & 1.058 & 0.56 & 0.001 & 0.382 & 0.540 \\
Management & 1.095 & 0.62 & 0.001 & 0.442 & 0.640 \\
Human Factor & 1.103 & 0.78 & 0.001 & 0.524 & 0.653 \\
\hline
\end{tabular}

Source: Authors

Table 4. Result of Structural Path

\begin{tabular}{lllll}
\hline Contruct & Items & Loadings & P-value & Sig. Level(5\%) \\
\hline \multirow{2}{*}{ Effective Communication } & CMQ1-Com & 0.75 & 0.010 & $* * *$ \\
& CMQ2-Com & 0.86 & 0.000 & $* * *$ \\
Organizational Culture & CMQ3-Com & 0.72 & 0.024 & $* * *$ \\
& MAQ4 -Cul & 0.82 & 0.000 & $* * *$ \\
Knowledge & KWQ6-Cul & 0.68 & 0.046 & $* *$ \\
Management & KWQ7-KW & 0.75 & 0.013 & $* * *$ \\
& MQ8-MA & 0.75 & 0.012 & $* *$ \\
& MQ9-MA & 0.86 & 0.000 & $* * *$ \\
Human Factor & MQ10-MA & 0.72 & 0.020 & $* * *$ \\
& CQ11-KW & 0.75 & 0.012 & $* * *$ \\
& CQ12-KW & 0.81 & 0.001 & $* * *$ \\
& CQ13-KW & 0.84 & 0.000 & $* * *$ \\
\hline
\end{tabular}

Source: Authors

$* *=5 \%$ significance and $* * *=1 \%$ significance 
contribute significantly in improving the lean efficiency outcome, such as knowledge sharing/team work, management support, respect for human, effective communication are among top factors encouraging successful adoption of lean. The study is also revealing that there is no simple model or framework for the successful implementation of lean in an organization and lean concept should be rather seen as a culture that integrate learning and improving process rather than a tool and methodology that is meant to solve all wide orgnizational problem. On the human side, the study concludes that effective teamwork, employee training and development, creating an enabling environment for employee to thrives, work flexibilities are key factors in employee adapting to the changes introduces by lean implementation.

The findings also revealed that there is the need for continuous training of staff to get them well acquitted with the organizational culture and promote effort to achieve overall organizational goals and objectives. The study equally reveals the power of effective communication in the overall organizational objectives.

\section{Competing Interests}

Authors declare no competing interest.

\section{References}

Abu, F., Gholami, H., Saman, M., Zakuan, N., Streimikiene, D. and Kyriakopoulos, G. (2021). An sem approach for the barrier analysis in lean implementation in manufacturing industries., Sustainability 13(1): 1-12.

URL: doi(https://doi.org/10.339o/su13041978)

Alkhoraif, A. and McLaughlin, P. (2018). Organizational culture aspects that facilitate lean implementation: a pilot study., Int. J. Agile Systems, Management 11(2): 103-125.

Allu, E. (2018). Advancing lean implementation for improving sustainability in sub-saharan africa: A literature review., Sustainability - The Journal of Record 11(3): 15-23.

URL: doi/10.1089/sus.2018.0003

Amade, B., Ononuju, C, N., Obodoh, D. and Okorie, C. E. (2019). Barriers to lean adoption for construction projects., The $\mathrm{Pa}$ cific Journal of Science, Technology 20(1): 153-166.

Andersen, H. and Rovik, K. (2015). Lost in translation: A case study of the travel of lean thinking in a hospital, Health Services Research 15(401): 1-8.

Asna, R., Nordin, N. and Othman, S. N. (2015). Managing change on lean implementation in service sector, Procedia - Social, Behavioural Sciences 211(1): 313-319.

Becker, J. M., Klein, K. and Wetzels, M. (2012). Hierarchical latent variable models in pls-sem: Guidelines for using reflective-formative type models., Long Range Plan. 45(1): 359-394.

URL: doi: $h$ ttp://doi.org/10.1016/j.lrp.2012.10.001

Bhamu, J. and Sangwan, K. (2014). Lean manufacturing: literature review, research issues, International Journal of Operations, Production Management 34(7): 876-940. URL: doi: http://doi.org/10.1016/j.lrp.2012.10.001

Bhasin, S. (2012). Prominent obstacles to lean, International Journal of Productivity, Performance Management 61(4): 403425.

Chanegrih, T. and Creusier, J. (2016). The effect of internal, external lean practices on performance: A firm-centered approach., Management International 21(1): 114-125.

Coetzee, R., Merwe, K. V. and Dyk, L. V. (2016). Lean implementation strategies: how are the toyota way princi- ples addressed?, South African Journal of Industrial Engineering 27(3): 79-91.

Duarte, P. and Amaro, S. (2018). Methods for modelling reflective-formative second order constructs in pls: An application to online travel shopping., J. Hosp. Tour. Technol. 9(1): 295-313.

Filho, M., Ganga, G. and Gunasekaran, A. (2016). Lean manufacturing in brazilian small, medium enterprises: implementation, effect on performance, International Journal of Production Research 54(24): 7523-7545.

URL: DOI:10.1080/00207543.2016.1201606

Garcia, J. and Bonavia, T. (2015). Relationship between employee involvement, lean manufacturing, its effect on performance in a rigid continuous process industry, International Journal of Production Research 53(11): 3260-3275.

Grove, A. L., Meredith, J. O., MacIntyre, M., Angelis, J. and Neailey, K. (2015). Ukhealth visiting: Challenges faced during lean implementation., Leadership in Health Services 23(3): 204-218.

Jasti, N. K. and Kodali, R. (2015). A critical review of lean supply chain management frameworks: proposed framework., Production Planning, Control 26(13): 1051-1068.

URL: https://doi.org/10.1080/o9537287.2015.1004563

Jayasingam, S., Fujiwara, Y. and Thurasamy, R. (2018). I am competent so i can be choosy': Choosiness, its implication on graduate employability., Stud. High. Educ. 43(1): 1119-1134. URL: $h t t p: / / d o i . o r g / 10.1080 / 03075079.2016 .1221918$

Kumar, R. (2014). The challenges to the implementation of lean manufacturing., International Journal of Engineering Science, Advanced Technology 4(4): 307-312.

Marodin, G. A. and Saurin, T. A. (2013). Implementing lean production systems: Research areas, opportunities for future studies., International Journal of Production Research 51(22): 6663-6680.

Mrugalska, B. and Wyrwicka, M. K. (2016). Leanness assessment: a literature review., International Journal of Operations, Production Management 36(10): 1115-1160.

Mrugalska, B. and Wyrwicka, M. K. (2017). Towards lean production in industry 4.0, Procedia Engineering 182(1): 466473.

Noori, B. (2015). The critical success factors for successful lean implementation in hospitals, Int. J. Productivity, Quality Management 15(1): 108-126.

Pakdil, F. and Leonard, K. M. (2015). The effect of organizational culture on implementingand sustaining lean processes, Journal of Manufacturing Technology Management 26(5): 725-743.

Peabody, E. (2019). Respect for people is key to lean-driven culture change.

URL: https://leanconstructionblog.com/Respect-for-People-isKey-to-Lean-Driven-Culture-Change.html

Ramadas, T. and Satish, K. P. (2015). Identification, modeling of process barriers: Implementing lean manufacturing in small-and medium-size enterprises, International Journal of Lean Six Sigma 2(1).

URL: $h$ ttp://doi.org/10.1108/IJLSS-o9-2016

Ridwan, D. and Joseph, E. T. (2021). Effects of bank charges on bank's customers saving and income in nigeria, Journal of Economics, Management 27(3): 1-11.

URL: DOI: $10.9734 / J E M T / 2021 / v 27 i 330331$

Scholtz, B., Mahmud, I. and Ramayah, T. (2016). Does usability matter? an analysis of the impact of usability on technology acceptance in erp settings, Interdiscip. J. Inf. Knowl. Manag. 11(1): 309-330.

URL: $h$ ttp://doi.org/10.28945/3591

Shepherd, L. (2016). Effective leadership underpins successful lean implementation.

URL: https://leanconstructionblog.com/Effective-leadership- 
8 Applied Journal of Economics, Management, and Social Sciences, 2021, Vol. 2, No. 1

underpins-successful-lean-implementation.html.

Stone, K. B. (2016). Four decades of lean: a systematic literature review, International Journal of Lean Six Sigma 3(2): 112132.
URL: doi: $10.1108 / 20401461211243702$

Warcup, R. (2015). Successful paths to becoming a lean organization in the construction industry. 